\title{
17-Hydroxyprogesterone Response to Standard Dose Synacthen Stimulation Test in CYP21A2 Heterozygous Carriers and Non-carriers in Symptomatic and Asymptomatic Groups: Meta-analyses
}

\author{
(D) Seher Polat ${ }^{1}$, (1) Yusuf Kemal Arslan² \\ ${ }^{1}$ Erzincan Binali Yıldırım University Faculty of Medicine, Department of Medical Genetics, Erzincan, Turkey \\ 2Erzincan Binali Yıldırım University Faculty of Medicine, Department of Biostatistics, Erzincan, Turkey
}

What is already known on this topic?

Standard dose synacthen stimulation test (SDSST) is a gold standard biochemical-screening test for evaluating adrenal gland function. Despite studies investigating the use of SDSST to identify heterozygous CYP21A2 mutation, the reliability of the test for this is still controversial.

\section{What this study adds?}

This meta-analysis was performed to determine if there were differences in 17-hydroxyprogesterone (17-OHP) response to SDSST (0.25 $\mathrm{mg}$ ) in the identification of CYP21A2 heterozygous carriers, with or without clinical sign of androgen excess disorders, to investigate the utility of the SDSST for this purpose and to determine the cut-off levels of 17-OHP for this purpose. The results support the hypothesis that stimulated 17-OHP level after SDSST had the potential to identify CYP21A2 carriers, although basal 17-OHP level was not sufficiently informative. Additionally, the median level of stimulated 17-OHP was higher in symptomatic mutation-free controls than in asymptomatic mutation-free healthy controls and similarly, the median level of stimulated 17-OHP was higher in symptomatic mutation carriers than in asymptomatic mutation carriers. Clinical phenotype may affect the evaluation of the test.

\begin{abstract}
Objective: Standard dose synacthen stimulation test (SDSST) is a gold standard screening test for evaluating adrenal gland function. Despite studies using SDSST to identify heterozygosity in CYP21A2, the reliability of the test for this purpose is still controversial. Therefore, the meta-analyses were performed to determine the differences in 17-hydroxyprogesterone (17-OHP) responses to standard dose (0.25 mg) SDSST in the diagnosis of CYP21A2 heterozygous individuals, with or without clinical signs of androgen excess disorders. Methods: PubMed and MEDLINE databases were searched. A total of 1215 subjects (heterozygous carriers $\mathrm{n}=669$, mutation-free controls $n=546$ ) were included in the meta-analyses.

Results: Basal 17-OHP median/mean levels were $4.156(3.05-10.5) / 5.241( \pm 2.59) \mathrm{nmol} / \mathrm{L}$ and $3.90(2.20-9.74) / 4.67( \pm 2.62) \mathrm{nmol} / \mathrm{L}$ in symptomatic heterozygous carriers and symptomatic mutation-free controls, respectively. Stimulated 17-OHP median/mean levels were $17.29(14.22-37.2) / 19.51( \pm 7.63) \mathrm{nmol} / \mathrm{L}$ and $9.27(7.32-15.9) / 10.77( \pm 3.48) \mathrm{nmol} / \mathrm{L}$ in symptomatic heterozygous carriers and symptomatic mutation-free controls, respectively. Basal 17-OHP median/mean levels were $3.21(2.64-4.78) / 3.33( \pm 0.84) \mathrm{nmol} / \mathrm{L}$ and $3.12(1.82-3.6) / 2.83( \pm 0.71) \mathrm{nmol} / \mathrm{L}$ in asymptomatic heterozygous carriers and asymptomatic mutation-free healthy controls, respectively. Stimulated 17-OHP median/mean levels were $14.16(12.73-16.37) / 14.16( \pm 1.37) \mathrm{nmol} / \mathrm{L}$ and $6.26(4.9-8.23) / 6.48( \pm 1.2)$ $\mathrm{nmol} / \mathrm{L}$ in asymptomatic heterozygous carriers and asymptomatic mutation-free healthy controls, respectively. The cut-off levels for stimulated $17-\mathrm{OHP}$ were $10.48 \mathrm{nmol} / \mathrm{L}$ and $13.48 \mathrm{nmol} / \mathrm{L}$ for asymptomatic heterozygous and symptomatic heterozygous, respectively. Conclusion: The meta-analyses support the idea that stimulated 17-OHP level has potential for use in identifying CYP21A2 carriers. Besides, considering differences in the basal and stimulated 17-OHP levels in symptomatic heterozygous individuals compared to those who were asymptomatic heterozygous could increase the accuracy of the test.
\end{abstract}

Keywords: Adrenal insufficiency, synacthen stimulation test, 17-OHP level, heterozygous, CYP21A2 


\section{Introduction}

Adrenal insufficiency is caused by a failure of the adrenal cortex to produce cortisol. The most common cause of adrenal insufficiency is autosomal recessive inherited congenital adrenal hyperplasia (CAH) (OMIM 201910), characterized by excess adrenal androgen production resulting from impairment of the adrenal 21 -hydroxylase $(21 \mathrm{OH})$ enzyme. Androgen excess affects approximately $10 \%$ of women (1). Disorders that result from hyperandrogenism include polycystic ovary syndrome (PCOS) (OMIM 184700) and $21 \mathrm{OH}$-deficient non-classic adrenal hyperplasia (21OHDNCAH) (OMIM 201910). The etiology of PCOS is not fully understood but it is a familial disorder that appears to be inherited as a complex genetic trait with a risk to siblings of $\sim 50 \%$. There is no accepted precise mode of inheritance $(2,3,4)$ but it is one of the most common endocrine disorders, affecting 6-10\% of reproductive-age women (5). It may be difficult to distinguish PCOS from NCAH clinically (6). Of hyperandrogenic women, $1-10 \%$ is reported to be affected by NCAH due to $21 \mathrm{OHD}$ and NCAH may even be asymptomatic (7). In childhood, hyperandrogenism may present with premature pubarche (PP) and $5-20 \%$ of PP cases were diagnosed with $\mathrm{NCAH}$, mainly due to $21 \mathrm{OHD}$ $\operatorname{NCAH}(8,9,10,11,12)$.

Standard dose synacthen stimulation test (SDSST) is the gold standard screening test to evaluate adrenal gland function (13). It is the principal challenge test to estimate the relative activity of adrenocortical enzymes (14) and it has been widely used for the biochemical diagnosis of $\mathrm{NCAH}$, due to various adrenocortical enzyme deficiencies including $21 \mathrm{OHD}$. A consensus is not available about whether heterozygous individuals with CYP21A2 mutations have a higher risk of developing clinical hyperandrogenism. In some selected populations, being heterozygous for CYP21A2 seems to be related to irregular menses, hirsutism, PCOS, premature adrenarche (PA), acne, and central precocious puberty $(12,15,16,17,18,19,20,21)$. In contrast, other investigators concluded that heterozygosity for CYP21 mutations did not increase the risk of clinical androgen excess above that expected in the general population $(22,23)$. The prevalence of asymptomatic carriers for the disease in the general population was estimated to range from 1:50 to as high as 1:16 (24) and even higher among Ashkenazi Jews, according to a single report (8). The frequency of mutation carriers of CYP21A2 was almost 1 in 4 in PP and hirsute groups $(21,25)$.

The objectives of this meta-analysis were to determine if there was a difference in 17-hydroxyprogesterone (17OHP) response to standard dose $(0.25 \mathrm{mg})$ SDSST in the diagnosis of CYP21A2 heterozygous individuals, with or without clinical androgen excess, to investigate the utility of the SDSST to identify heterozygous CYP21A2 carriers and to determine the cut-off levels of $17-\mathrm{OHP}$ for this purpose.

\section{Methods}

\section{Search Strategy}

PubMed and MEDLINE databases were searched for relevant literature. The search strategy was kept broad, included several synonymous expressions, and performed using the keywords (" 21 -hydroxylase" OR "CYP21A2" OR "21 $\alpha$-hydroxylase" OR "CYP21") AND "heterozygous" AND ["hirsutism" OR "hyperandrogenemia" OR "polycystic ovary syndrome" OR "PCOS" OR "acne" OR "alopecia" OR "oligomenorrhea" OR "adrenal hyperplasia" OR "adrenocorticotropic hormone (ACTH)]". Only peerreviewed, original articles were included in the study. Additional publications from the references of the included studies were manually searched by the investigators to identify the articles that may be missed by the electronic search.

\section{Study Selection}

Human studies, published between January 1995 and May 2020, were considered further. Studies without control groups were excluded, as well as those written in languages other than English. Since genetic mutation screening performed before 1995 was based on human leukocyte antigen (HLA) typing in most cases, studies performed before this date were excluded from the search criteria.

In the publications included in the study, mutation analyses were performed using a range of methods, including amplification-refractory mutation system, allele-specific oligonucleotide hybridization, Sanger sequencing, singlestrand conformation polymorphism, multiplex ligationdependent probe amplification, Southern Blot, sequencespecific oligonucleotide probes, real-time quantitative reverse transcription-polymerase chain reaction and multiplex mini-sequencing. 17-OHP measurement was done using radioimmunoassay (RIA), enzyme-linked immunosorbent assay, and liquid chromatography with tandem mass spectrometry (LC-MS/MS) methods.

The selection criteria were: 1) case-control studies; 2) studies that evaluated the relationship between basal and/or stimulated 17-OHP levels after SDSST in CYP21A2 carriers and non-carriers with one of the clinical hyperandrogenic symptoms including hirsutism, and/or oligo/amenorrhea 
and/or acne and/or elevation of at least one serum androgen; 3) useable data on 17-OHP levels to identify $21 \mathrm{OH}$ deficiency in patients with PP, PA and premature thelarche (PT); and 4) studies focused on differential diagnosis between NCAH and PCOS. The exclusion criteria were: 1) case or family reports; 2) studies that evaluated genetically confirmed $\mathrm{CAH}$ and NCAH patients; 3) studies focused on diagnosis, treatment, review, method and general information; and 4) studies related to other diseases including Cushing syndrome, acromegaly, adrenal tumor, 11-hydroxylase, cytochrome P450 oxidoreductase (POR), 3-beta ( $\beta$ )-hydroxysteroid dehydrogenase (HSD3B2), and 17 $\alpha$-hydroxylase/1 7,20-lyase (CYP17A1) deficiencies (Figure 1).

\section{Data Extraction and Analysis}

Two authors independently screened the title, abstract and full text of potentially eligible studies twice at two different time points. Any disagreements were resolved by discussion or by seeking an independent third opinion. The titles and abstracts of the articles were examined and irrelevant ones were excluded. The full texts of the remaining articles were reviewed to find relevant studies that met the inclusion criteria. The Preferred Reporting Items for Systematic Reviews and Meta-Analyses guideline is aimed at improving systematic reviews and formed the basis for the selection protocol used in the current study (Figure 1).

\section{Statistical Analysis}

For all meta-analyses, Review Manager (2014) version, 5.3 was used. A random-effects model and fixed-effect model were used while performing the meta-analyses. Due to the large degree of heterogeneity, a random-effects model was applied, which does not adjust heterogeneity but it is a more conservative approach when the heterogeneity exists. Summary statistics were reported as standardized mean difference (SMD) and mean difference (MD) with $95 \%$ confidence intervals $(\mathrm{CI})$. SMD levels of $<0.2$, $>0.2$ and $<0.7$, or $>0.8$ were considered small and moderate, or large effects, respectively (26). Study-level mean (standard deviation; SD) and median (minimummaximum) levels were reported. Study-level mean levels were used to generate receiver operating characteristic (ROC) curve using Statistical Package for the Social

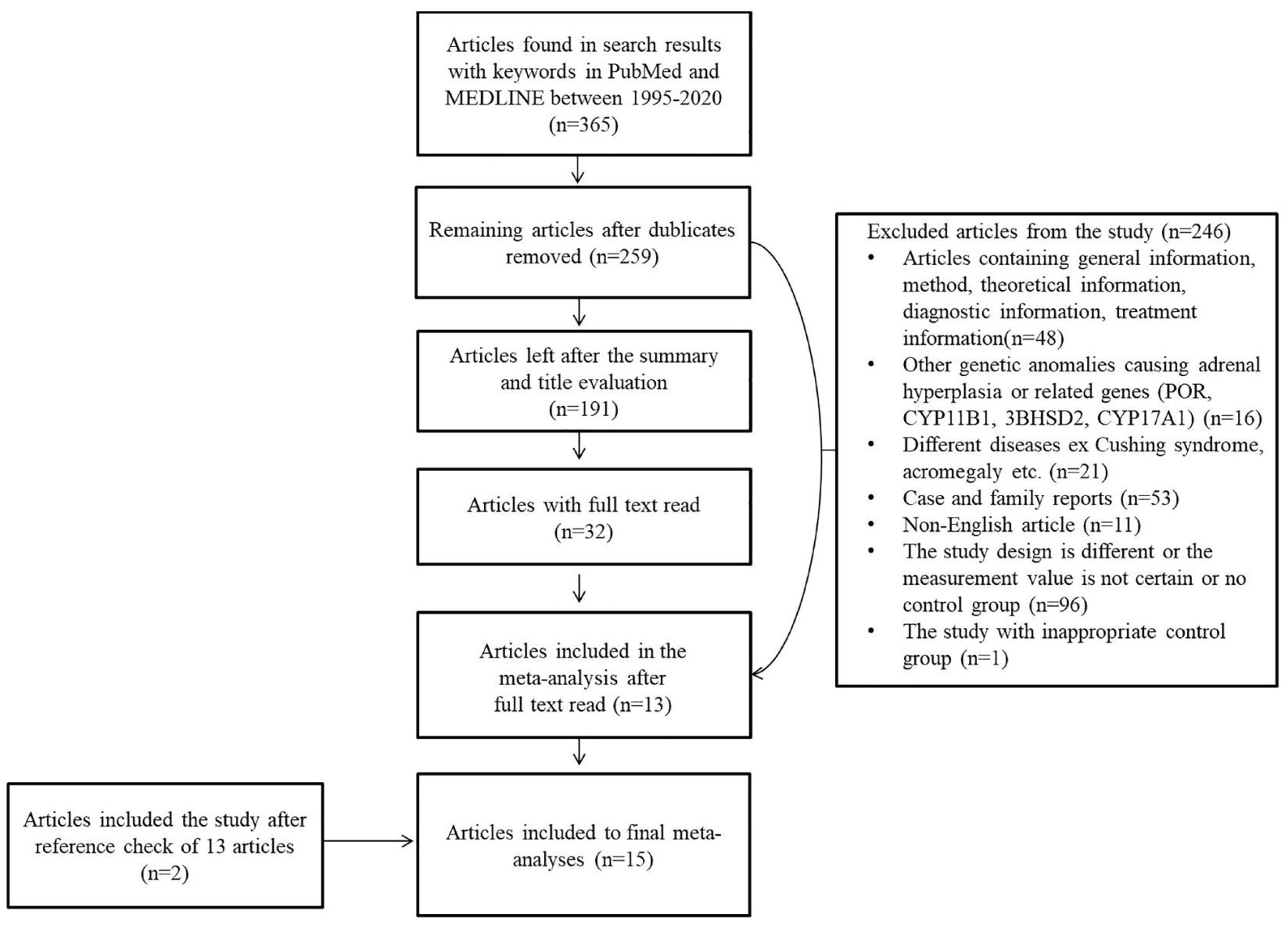

Figure 1. Flow chart to illustrate the process by which articles were selected or rejected based on the inclusion and exclusion criteria of the study 
Sciences, version 22 (IBM Inc., Armonk, NY, USA) (27). When cut-off values were determined, Youden's index was used and diagnostic accuracy measures are reported.

To convert all reported results to a standard units of measurement $(\mathrm{nmol} / \mathrm{L})$ in all the included articles, the 17-OHP values were multiplied by 0.0303 and 3.0261 to convert $\mathrm{ng} / \mathrm{dL}$ to $\mathrm{nmol} / \mathrm{L}$ and $\mathrm{ng} / \mathrm{ml}$ to $\mathrm{nmol} / \mathrm{L}$, respectively.
Patients

Individuals from both "female and male" gender, who were CYP21A2 heterozygous mutation carriers and non-carriers and aged between 0.7-65 years, were included in the study (Table 1). The study groups consisted of females and/or males with PCOS, PP, PA, PT and clinical hyperandrogenism, relatives of patients with $\mathrm{CAH}$ or $\mathrm{NCAH}$, and healthy controls.

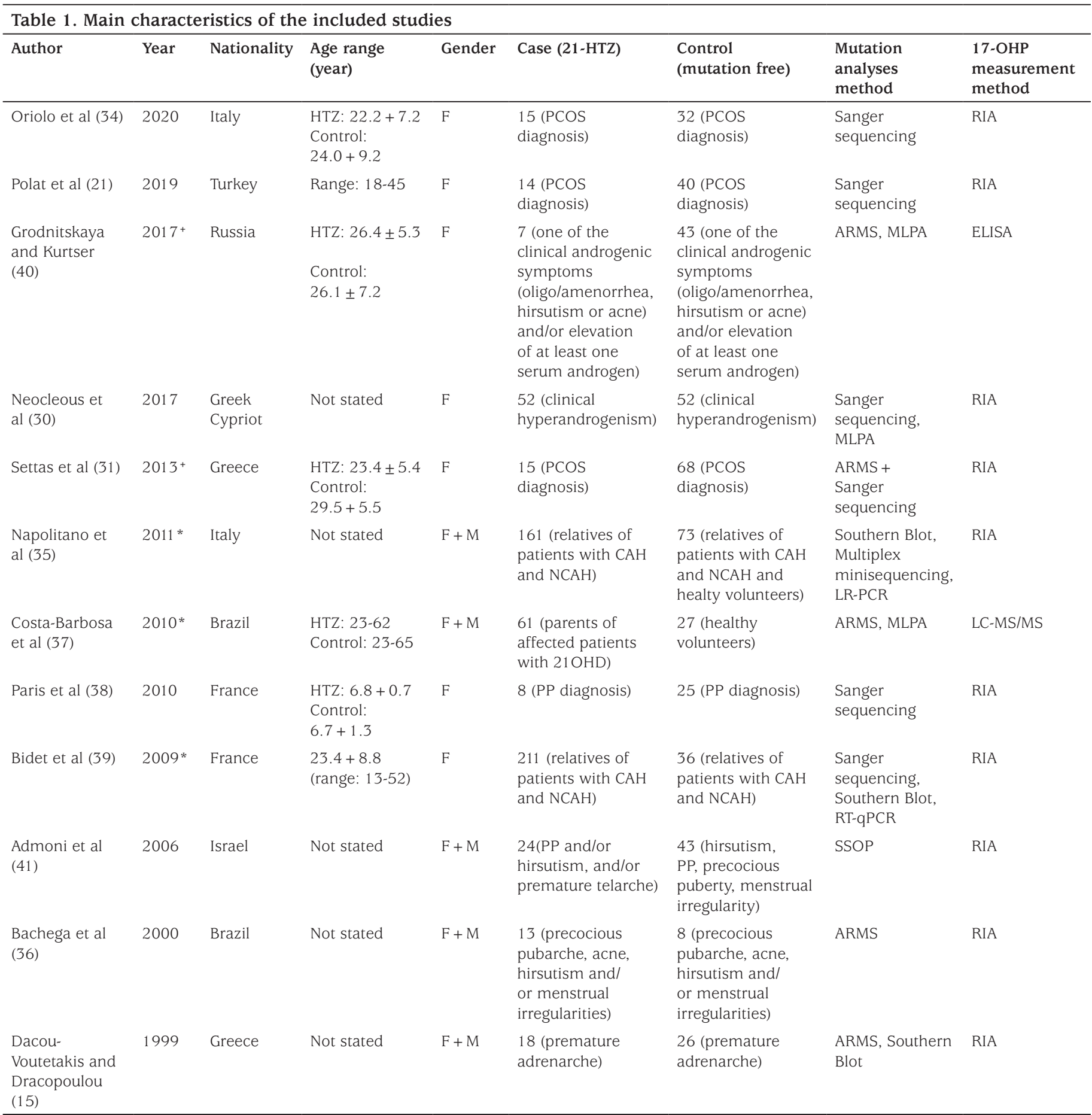




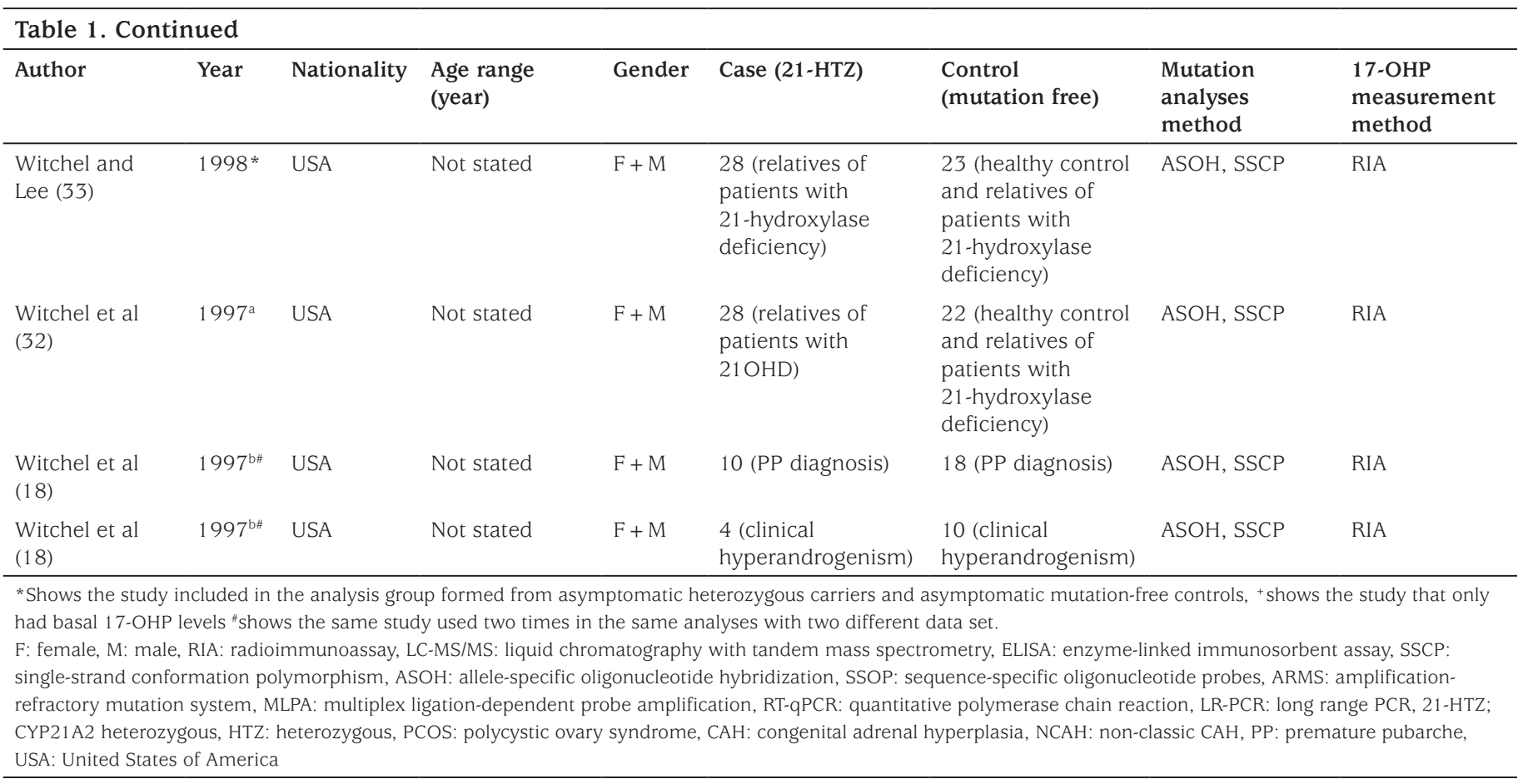

SMutation analysis of the CYP21A2 gene and SDSST were applied to all volunteers participating in the study.

\section{Heterogeneity and Publication Bias}

Between-study variability was compared for within-study variability (i.e., heterogeneity of effect size) using the $\mathrm{I}^{2}$ statistic, which measures the percentage of variation due to heterogeneity (28). An $\mathrm{I}^{2}$ level less than $25 \%$ indicated low heterogeneity, whereas levels between 35 to $50 \%$ showed moderate heterogeneity and those above $50 \%$ showed high heterogeneity (28). Publication bias was assessed using contour-enhanced funnel plots (29).

\section{Results}

\section{Search Results}

Three hundred and sixty-five relevant publications were found after the screening of studies published between 1995 and 2020. After excluding repetitive and irrelevant publications, fifteen high-quality, peer-reviewed publications that met inclusion criteria were included in the meta-analysis. These studies were carried out in Europe, the United States of America, and Russia. Three studies were carried out in Greece $(15,30,31)$, three in the United States of America $(18,32,33)$, two in Italy $(34,35)$, two in Brazil $(36,37)$, two in France $(38,39)$, one in Turkey (21), one in Russia (40) and one in Israel (41). CYP21A2 mutation analysis and basal and/or stimulated 17-OHP measurements were available in all study subjects. The SDSST was performed in patients by administration of a single, intravenous dose of $0.25 \mathrm{mg}$ synacthen (synthetic ACTH). Measurements of the basal and stimulated serum 17-OHP levels were done after 30 or 60 minutes of synacthen administration.

Among the included studies, two were added to the relevant sub-analysis since they only included basal 17 OHP measurements $(31,40)$. Two different control groups were identified in the included studies; a mutation-free asymptomatic healthy volunteer group (asymptomatic heterozygous vs. asymptomatic mutation-free healthy control), and a mutation-free but clinically symptomatic volunteer group (symptomatic heterozygous vs. symptomatic mutation-free control). Therefore, these two control subgroups were analysed in two separate analyses to make clear discrimination. In a study, since 17-OHP levels were given separately based on two different clinical findings, the same study was included twice with different data sets (18). Whereas 17-OHP level measured in a publication was remarkably high in both groups compared to given 17-OHP levels in other publications used in the meta-analysis, the study was included in the analysis since it met the inclusion criteria (36). One thousand, two hundred and fifteen subjects including $21 \mathrm{OH}$-heterozygous carriers $(n=669)$ and mutation-free controls $(n=546)$ were included in the meta-analysis (Table 1). 


\section{Comparison of Basal and Stimulated 17-0HP Levels}

\section{Symptomatic Heterozygous vs. Symptomatic Mutation-free Control}

The fixed-effects model was used with basal 17-OHP levels because the heterogeneity of the studies was low $\left(\mathrm{I}^{2}=0 \%\right.$, $p=0.620$ ). In the symptomatic heterozygous carriers, the level of the MD was found to be higher than symptomatic mutation-free controls (MD: $0.70 \mathrm{nmol} / \mathrm{L}, 95 \% \mathrm{CI}: 0.21$ $1.18, \mathrm{Z}=2.81, \mathrm{p}=0.005)$. When the MD was standardized, the difference was determined to have a medium effect size (SMD: $0.33 \mathrm{nmol} / \mathrm{L}, 95 \% \mathrm{CI}: 0.14-0.51, \mathrm{Z}=3.42, \mathrm{p}<0.001$ ) (Figure 2).

When comparing the stimulated levels of 17-OHP in symptomatic heterozygous carriers and symptomatic mutation-free controls, the random-effects model was used due to significant heterogeneity $\left(\mathrm{I}^{2}=72 \%, \mathrm{p}<0.001\right)$. The MD were found to be higher in heterozygous carriers (MD: $7.20 \mathrm{nmol} / \mathrm{L}, 95 \% \mathrm{CI}: 5.15-9.25, \mathrm{Z}=6.87, \mathrm{p}<0.001$ ). The SMD (SMD: $0.9 \mathrm{nmol} / \mathrm{L}, 95 \% \mathrm{CI}: 0.46-1.34, \mathrm{Z}=4.01$, $p<0.001$ ) shows that the difference has a large effect size (Figure 2).

The ROC curves for symptomatic heterozygous and symptomatic mutation-free controls are shown in Figures 3A, 3B, demonstrating that stimulated 17-OHP provides good discrimination (area under ROC curve $=0.80$, $\mathrm{p}=0.034$ ) between symptomatic heterozygous and symptomatic mutation-free controls, with an optimal cutoff of $13.41 \mathrm{nmol} / \mathrm{L}$, yielding a sensitivity of $100 \%$ and a specificity of $66.7 \%$. Basal 17-OHP level was not found to be capable of discriminating heterozygous from wild type in the symptomatic group (Table 2).

\section{Asymptomatic Heterozygous vs. Asymptomatic Mutation-free Healthy Control}

The fixed-effects model was used in the analysis of basal 17 OHP levels in asymptomatic heterozygous carriers with the asymptomatic mutation-free healthy controls due to the low heterogeneity of the studies $\left(I^{2}=0 \%, p=0.53\right)$. Basal 17 OHP level was higher in asymptomatic heterozygous carriers than in asymptomatic mutation-free healthy controls (MD: $0.62 \mathrm{nmol} / \mathrm{L}, 95 \% \mathrm{CI}: 0.20-1.04, \mathrm{Z}=2.92, \mathrm{p}<0.001)$. The SMD in the groups was $0.27 \mathrm{nmol} / \mathrm{L}$ (SMD: $0.27,95 \% \mathrm{CI}$ : $0.10-0.45, Z=3.04, p=0.002$ ), and this difference was determined to have a medium effect size (Figure 4).

When comparing the stimulated level of $17-\mathrm{OHP}$ in asymptomatic heterozygous carriers and asymptomatic mutation-free healthy controls, the random-effects model was used due to significant heterogeneity $\left(\mathrm{I}^{2}=85 \%\right.$, $\mathrm{p}<0.001$ ). The 17 -OHP level was higher in asymptomatic

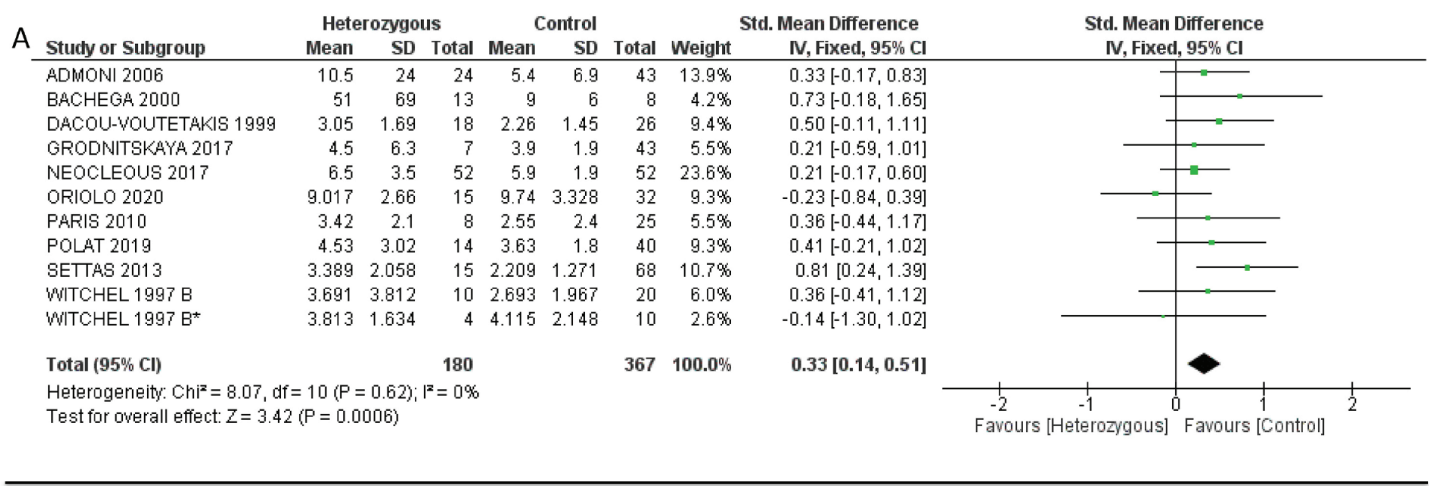

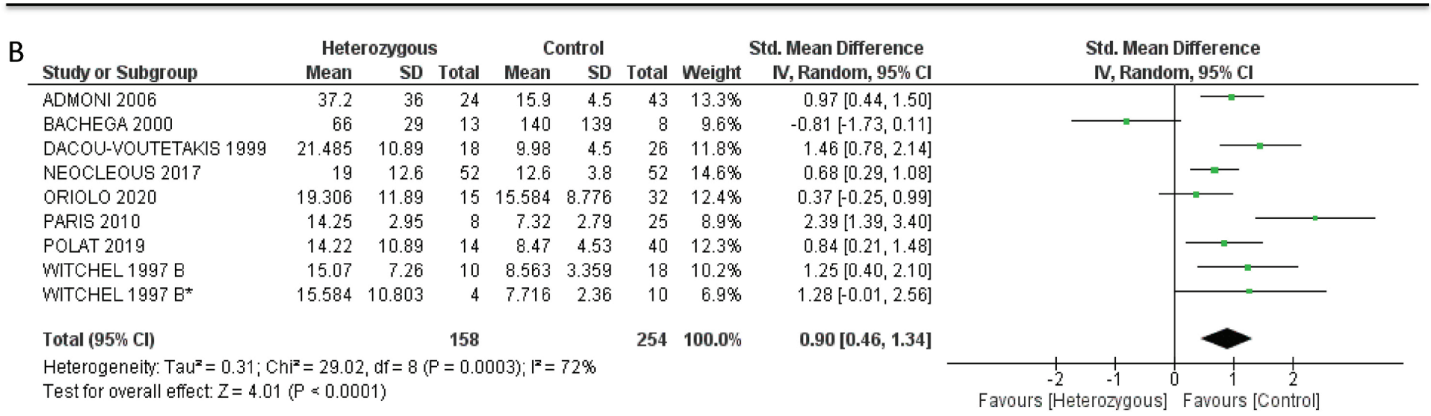

Figure 2. Forest plot of 17-hydroxyprogesterone response to standard dose synacthen stimulation test of symptomatic heterozygous vs. symptomatic mutation-free volunteers

*Shows the same study used two times in the same analyses with two different data set

CI: Confidence interval, SD: Standard deviation 
heterozygous carriers than in asymptomatic mutation-free healthy controls (MD: $7.57 \mathrm{nmol} / \mathrm{L}, 95 \% \mathrm{CI}:$ 6.82-8.32). The $\mathrm{SMD}$ in the groups was $1.34 \mathrm{nmol} / \mathrm{L}$ (SMD: $1.34,95 \% \mathrm{CI}$ : $0.81-1.87, Z=4.99, p<0.001$ ), and the effect size for this difference was similar to the symptomatic heterozygous vs. symptomatic mutation-free controls comparison (Figure 4).

The ROC curves for asymptomatic heterozygous and asymptomatic mutation-free healthy controls are shown in Figures 3C, 3D, demonstrating that stimulated 17-OHP provided good discrimination (area under $\mathrm{ROC}$ curve $=1.0$,
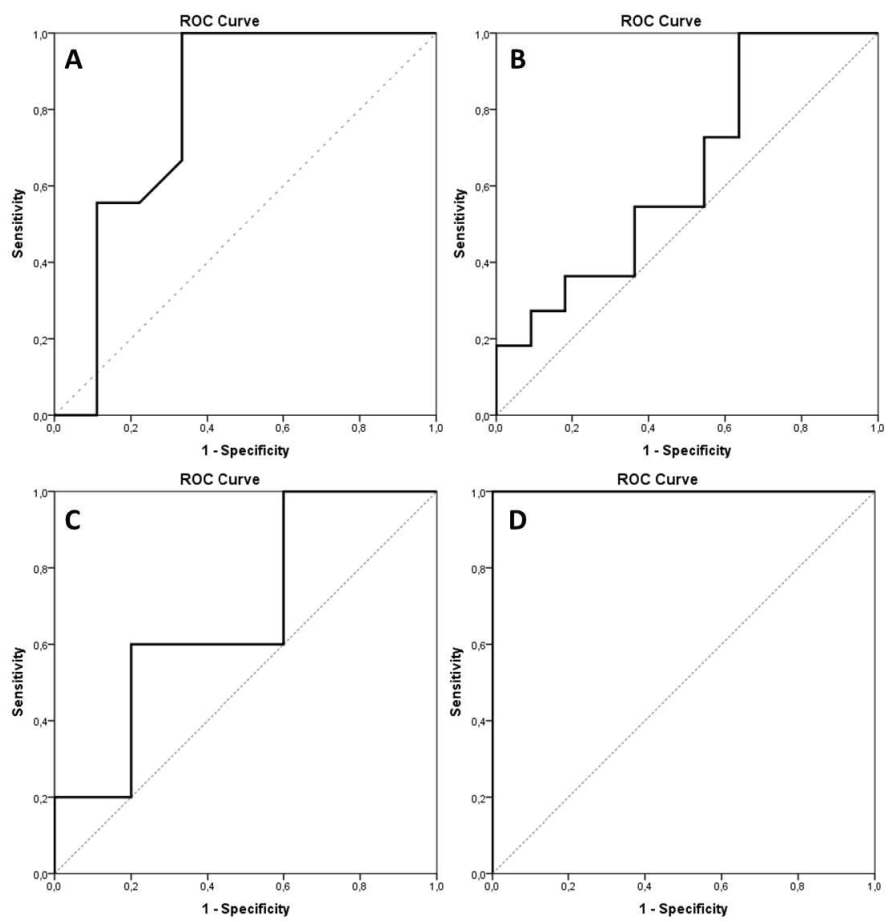

Figure 3. Receiver operating characteristic-curve analysis for basal and stimulated 17-hydroxyprogesterone (17-OHP) levels in symptomatic and asymptomatic groups. A: Basal 17-OHP levels of symptomatic heterozygous vs. symptomatic mutationfree volunteers B: Stimulated 17-OHP levels of symptomatic heterozygous vs. symptomatic mutation-free volunteers C: Basal 17-OHP levels of asymptomatic heterozygous vs. asymptomatic mutation-free healthy volunteers D: Stimulated 17-OHP of asymptomatic heterozygous vs. asymptomatic mutation-free healthy volunteers $\mathrm{p}=0.009$ ) between asymptomatic heterozygous and asymptomatic mutation-free healthy control with an optimal cut-off of $10.48 \mathrm{nmol} / \mathrm{L}$, yielding a sensitivity of $100 \%$ and a specificity of $100 \%$. Basal 17-OHP level was not found to be capable of discriminating heterozygous from wild type in the asymptomatic group (Table 2).

\section{Median and Mean of Basal and Stimulated 17-0HP Levels}

Study-level median and mean were calculated, after elimination of the publication with extreme basal and stimulated 17-OHP levels (36). Basal 17-OHP median (range) levels were 4.156 (3.05-10.5) $\mathrm{nmol} / \mathrm{L}$ and 3.90 (2.20-9.74) $\mathrm{nmol} / \mathrm{L}$ in symptomatic heterozygous carriers and symptomatic mutation-free controls, respectively. Basal $17-O H P$ mean \pm SD levels were $5.24 \pm 2.59 \mathrm{nmol} / \mathrm{L}$ and $4.67 \pm 2.62 \mathrm{nmol} / \mathrm{L}$ in symptomatic heterozygous carriers and symptomatic mutation-free controls, respectively. Stimulated 17-OHP median levels were 17.29 (14.22$37.2) \mathrm{nmol} / \mathrm{L}$ and $9.27(7.32-15.9) \mathrm{nmol} / \mathrm{L}$ in symptomatic heterozygous carriers and symptomatic mutation-free controls, respectively. Stimulated 17-OHP mean levels were $19.51 \pm 7.63 \mathrm{nmol} / \mathrm{L}$ and $10.77 \pm 3.48 \mathrm{nmol} / \mathrm{L}$ in symptomatic heterozygous carriers and symptomatic mutation-free controls, respectively. Basal 17-OHP median levels were $3.21(2.64-4.78) \mathrm{nmol} / \mathrm{L}$ and $3.12(1.82-3.6) \mathrm{nmol} / \mathrm{L}$ in asymptomatic heterozygous carriers and asymptomatic mutation-free healthy controls, respectively. Basal 17-OHP mean levels were $3.33 \pm 0.84 \mathrm{nmol} / \mathrm{L}$ and $2.84 \pm 0.71 \mathrm{nmol} / \mathrm{L}$ in asymptomatic heterozygous carriers and asymptomatic mutation-free healthy controls, respectively. Stimulated 17-OHP median levels were 14.16 (12.73-16.37) nmol/L and $6.26(4.9-8.23) \mathrm{nmol} / \mathrm{L}$ in asymptomatic heterozygous carriers and asymptomatic mutation-free healthy controls, respectively (Figure 5). Stimulated 17-OHP mean levels were $14.16 \pm 1.37 \mathrm{nmol} / \mathrm{L}$ and $6.48 \pm 1.2 \mathrm{nmol} / \mathrm{L}$ in asymptomatic heterozygous carriers and asymptomatic mutation-free healthy controls, respectively.

\section{Heterogeneity and Publication Bias}

Funnel plots were drawn in both fixed and random-effect models to determine whether there was a publication

\begin{tabular}{|c|c|c|c|c|c|c|}
\hline SDSST & AUC & $95 \% \mathrm{CI}$ for AUC & $\mathrm{p}$ & Cut-off value* & Sensitivity & Specificity \\
\hline Basal 17-OHP symptomatic & 0.67 & $0.39-0.87$ & 0.279 & - & - & - \\
\hline Basal 17-OHP asymptomatic & 0.68 & $0.33-1.0$ & 0.347 & - & - & - \\
\hline Stimulated $17-\mathrm{OHP}$ asymptomatic & 1.0 & $1.0-1.0$ & 0.009 & 10.48 & 100 & 100 \\
\hline
\end{tabular}

* ROC curve analysis from study-level data.

SDSST: standard dose synacthen stimulation test, AUC: area under ROC curve, CI: confidence interval, 17-OHP: 17-hydroxyprogesterone, ROC: receiver operating characteristic 


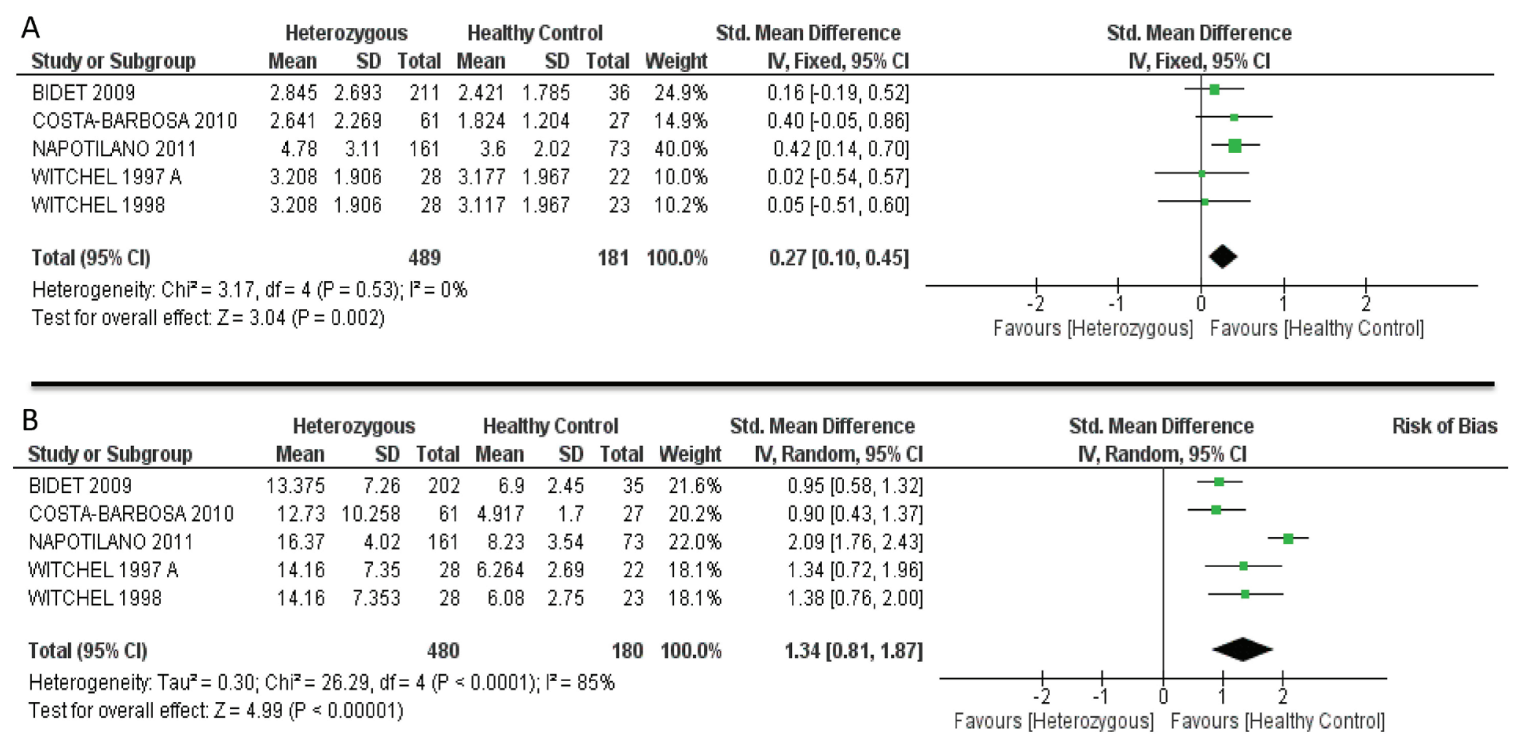

Figure 4. Forest plot of 17-hydroxyprogesterone response to standard dose synacthen stimulation test in asymptomatic heterozygous vs. asymptomatic mutation-free healthy controls
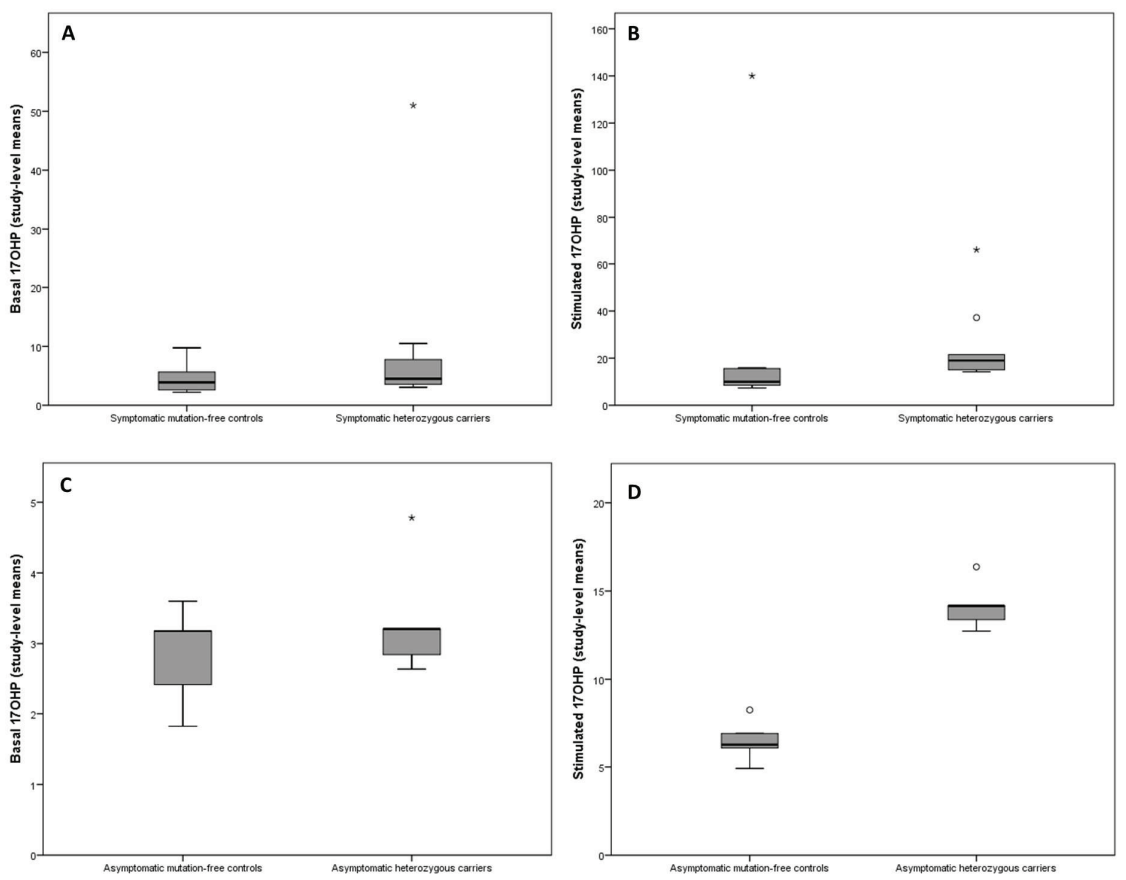

Figure 5. Box plot for median of basal and stimulated 17-hydroxyprogesterone levels in symptomatic and asymptomatic groups

bias in the included papers. In both models, CI were also presented in the funnel plot. As funnel plots seemed almost symmetrical in all meta-analyses, it was concluded that publication bias was weak (Figure 6).

\section{Discussion}

Measurement of serum 17-OHP was introduced in 1968 (42), and it is now used most widely for the diagnosis of adrenal enzymatic defects (43) in combination with SDSST, a gold standard and commonly used biochemical test in the evaluation of adrenal gland function. The SDSST for evaluation of adrenal gland function has been investigated in various clinical conditions, such as pre-clinical Addison's disease (44), immediately after pituitary surgery (45), patients with primary hypothyroidism (46), and in patients with primary fibromyalgia syndrome (47), in women with PCOS (48) and hirsutism and/or oligomenorrhea (49), 

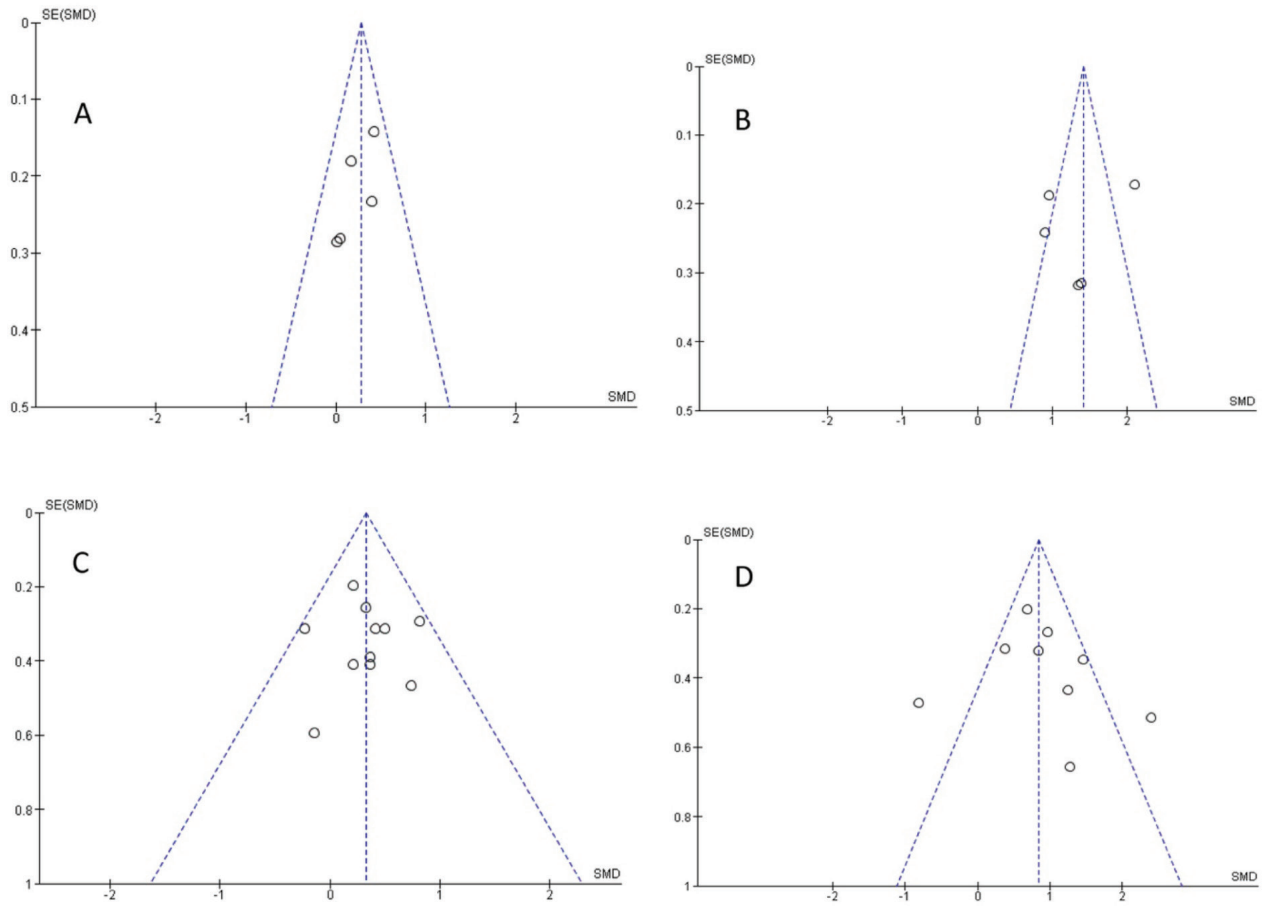

Figure 6. Funnel plots to detect publication bias of the meta-analysis. A: Basal 17-hydroxyprogesterone (17-OHP) levels of asymptomatic heterozygous vs. asymptomatic mutation-free healthy volunteers B: Stimulated 17-OHP levels of asymptomatic heterozygous vs. asymptomatic mutation-free healthy volunteers C: Basal 17-OHP levels of symptomatic heterozygous vs. symptomatic mutation-free volunteers D: Stimulated 17-OHP of symptomatic heterozygous vs. symptomatic mutation-free volunteers. The standardized mean difference (SMD) on the X-axis is plotted against the standard error of the SMD on the y-axis. Symmetrical distribution of studies indicates the absence of publication bias

in adolescents with PP (15), and in patients with $\mathrm{CAH}$ or NCAH (50). Compared to normal female individuals, female carriers of 21-OHD frequently demonstrate an exaggerated secretion of the $21-\mathrm{OH}$ precursor $17-\mathrm{OHP}$ after ACTH administration (51). It has been reported that $50-80 \%$ of carriers exhibit $17-$ OHP levels above the $95^{\text {th }}$ percentile of the control level after ACTH stimulation $(51,52,53)$.

To our knowledge, this is the first meta-analysis of differences in 17-OHP responses to SDSST in heterozygous and mutation-free symptomatic and asymptomatic volunteers, considering only high-quality studies with the same SDSST criteria and CYP21A2 mutation analyses at a molecular level excluding HLA typing. In the literature, SDSST was recommended when the basal $17-\mathrm{OHP} \geq 6 \mathrm{nmol} / \mathrm{L}$. So 21 OHD-NCAH was unlikely in cases with lower basal 17 OHP has become widely accepted. Possible heterozygote carrier status was considered for the patients with baseline 17 -OHP $>6 \mathrm{nmol} / \mathrm{L}$ or those with baseline 17 -OHP $<6$ $\mathrm{nmol} / \mathrm{L}$ and ACTH stimulated $17-\mathrm{OHP}<30 \mathrm{nmol} / \mathrm{L}(54,55)$. Stimulated $17-\mathrm{OHP}>30 \mathrm{nmol} / \mathrm{L}$ was considered as the criterion for $21 \mathrm{OH}$ deficiency-related NCAH (56). In another study, patients were considered to be heterozygote carriers of $21 \mathrm{OHD}$ with ACTH-stimulated 17-OHP concentrations between $12.1 \mathrm{nmol} / \mathrm{L}$ and $30.2 \mathrm{nmol} / \mathrm{L}$ (57). In yet another study, stimulated 17-OHP levels $>45 \mathrm{nmol} / \mathrm{L}$ after ACTH stimulation were suggested to have NCAH while levels between 15 and $45 \mathrm{nmol} / \mathrm{L}$ were suggested to be probable mutation carriers and levels below $15 \mathrm{nmol} / \mathrm{L}$ were interpreted as normal (41).

In our study, MD and SMD of the basal 17-OHP were $0.7 \mathrm{nmol} / \mathrm{L}$ and $0.33 \mathrm{nmol} / \mathrm{L}$ in the symptomatic group while MD and SMD in the asymptomatic group were 0.62 $\mathrm{nmol} / \mathrm{L}$ and $0.27 \mathrm{nmol} / \mathrm{L}$ compared to the control group, respectively. SMD levels in both groups were slightly higher than the small effect size limit of $<0.2$. In our meta-analyses, in the asymptomatic group, both the basal median 17-OHP level and the SMD level were found to be lower than in the symptomatic group. The authors of some of the included studies had attempted to identify a cutoff level for basal 17-OHP that will exclude the diagnosis of NCAH and avoid unnecessary SDSST, especially for countries where synthetic ACTH is not widely available (58). Temeck et al (59) found that $13-14 \%$ of patients with $\mathrm{NCAH}$ would be missed if a basal $17-\mathrm{OHP}$ level of $6 \mathrm{nmol} / \mathrm{L}$ 
was used. Escobar-Morreale et al (60) proposed a cutoff level of $5.1 \mathrm{nmol} / \mathrm{L}$ with $100 \%$ sensitivity and $88.6 \%$ specificity in a cohort of women with hyperandrogenism. Leite et al (11) showed that basal level of 17-OHP $>3$ $\mathrm{nmol} / \mathrm{L}$ was sufficient for the diagnosis of NCAH. Gönç et al (61) determined that only one of the NCAH cases would be missed when $4.69 \mathrm{nmol} / \mathrm{L}$ was used as the basal 17 OHP cut-off level in patients with PA and these authors also suggested that including the patient's clinical phenotype in the evaluation of the basal 17-OHP level can increase the accuracy of the SDSST. On the other hand, there is no consensus for identification of heterozygosity, and so 17-OHP levels between those of $\mathrm{NCAH}$ and normal are accepted as indicating heterozygousity (41).

In these meta-analyses, MD and SMD of the stimulated 17-OHP were $7.2 \mathrm{nmol} / \mathrm{L}$ and $0.9 \mathrm{nmol} / \mathrm{L}$ in the symptomatic group, and $7.57 \mathrm{nmol} / \mathrm{L}$ and $1.34 \mathrm{nmol} / \mathrm{L}$ in the asymptomatic group, respectively. SMD levels in both groups were higher than the large effect size limit of $>0.8$. The stimulated 17-OHP median levels were determined to be $17.29 \mathrm{nmol} / \mathrm{L}(14.22-37.2)$ and 9.27 $\mathrm{nmol} / \mathrm{L}$ (7.32-15.9) in symptomatic heterozygous carriers and symptomatic mutation-free controls, respectively, and median stimulated 17-OHP levels were 14.16 $\mathrm{nmol} / \mathrm{L}$ (12.73-16.37) and $6.26 \mathrm{nmol} / \mathrm{L}$ (4.9-8.23) in asymptomatic heterozygous carriers and asymptomatic mutation-free healthy controls, respectively. ROC analysis showed that the basal 17-OHP level was not discriminative in both symptomatic and asymptomatic groups, but the stimulated 17-OHP level was informative. The cut-off level for the asymptomatic heterozygous individuals was $10.48 \mathrm{nmol} / \mathrm{L}$, while the cut-off level for the symptomatic group was $13.41 \mathrm{nmol} / \mathrm{L}$. Both the cut-off levels were lower than $15 \mathrm{nmol} / \mathrm{L}$, which were interpreted as normal. Besides, the stimulated 17-OHP median level of symptomatic mutation-free controls was higher than that of asymptomatic mutation-free healthy controls (9.27 vs. $6.26 \mathrm{nmol} / \mathrm{L})$. Similarly, the stimulated $17-\mathrm{OHP}$ median level of symptomatic heterozygous carriers was higher than that of asymptomatic heterozygous carriers (17.29 vs. $14.16 \mathrm{nmol} / \mathrm{L})$. The stimulated 17-OHP level of the symptomatic group was in the heterozygous range ( $>15 \mathrm{nmol} / \mathrm{L}$ and $<45 \mathrm{nmol} / \mathrm{L}$ ), while it was below the level considered heterozygous $(<15 \mathrm{nmol} / \mathrm{L})$ in the asymptomatic group. This result supports the hypothesis that clinical phenotype effects the test. Similarly, Admoni et al (41) made a comparison between symptomatic heterozygous and family member carriers, which revealed that the symptomatic carriers had a significantly higher ACTH-stimulated 17-OHP than family member carriers.
CYP21A2 gene mutation is not the only factor causing androgen excess symptoms. Other hormones or genes may also play a role, resulting in a similar clinical phenotype. Additionally, both adrenal and gonadal steroid hormone biosynthesis is a complex phenomenon, regulated by the feedback mechanism between different tissues and dozens of genes belonging to different gene families. The biosynthetic pathways have not been fully elucidated yet and there is still much to be understood (62).

The CYP21A2 heterozygous mutation carrier should be considered in the differential diagnosis of hyperandrogenic symptoms (63). Determination of carrier status is also compulsory for genetic counselling of the parents affected by $\mathrm{CAH} / \mathrm{NCAH}$ and in families that includes a parent with confirmed heterozygous mutation, since genetic counselling plays an important role in the control of genetic diseases. The heterozygous individuals may be diagnosed with NCAH due to false-positivity of the SDSST, especially in V281 L heterozygous mutation (21). Therefore, there is a need for up-to-date studies on the specificity and sensitivity of the SDSST to distinguish CYP21A2 carriers and 21OHD$\mathrm{NCAH}$.

The V281 L mutation is compatible with the NCAH allele and the resulting protein exhibits $30-50 \%$ residual enzymatic activity (64). It has been shown that the ACTH test result gave a level close to the cut-off level used for NCAH in heterozygous V281L mutation $(21,41)$. Escobar-Morreale et al (23) hypothesized one possible explanation for the abnormal 21-hydroxylase function in subjects with one normal allele and a "half functioning" allele was a dominantnegative mutation. This is postulated to happen because the product of a mutation adversely affects the wild-type gene product within the same cell, as seen in different diseases such as familial hypertrophic cardiomyopathy (65) and alfamannosidosis (66).

Considering the developing technology, more precise basal and stimulated 17-OHP cut-off levels can be identified because it will be possible to combine genetic analysis, now more widely available and less expensive, with more precise hormone measurements obtained through LC/MS-MS. This kind of work can be valuable under conditions in which hormone determinations are possible but access to genetic testing is limited due to financial restrictions of health care systems or health insurance. Moreover, the SDSST is faster and cheaper than genetic analyses. We suggest that adding the clinical phenotype and the type of mutation to basal and stimulated 17-OHP evaluation may increase the accuracy of the test and yield better results. 


\section{Study Limitations}

Our study had a few limitations. Firstly, the included articles did not report data separately by gender. Secondly, the ages of the subjects in the included publications varied widely. Thirdly, copy number variation of CYP21A2 was not investigated in all studies included. Fourthly, study assays, number of individuals and 17-OHP units differed between included studies. Our study also had some strengths. Firstly, a genetic analysis was performed in all the subjects. Secondly, almost all 17-OHP measurements were performed by using the same hormone measurement method (RIA), with the exception of two studies $(37,40)$.

\section{Conclusion}

In conclusion, this meta-analysis supports the idea that stimulated 17-OHP level has the potential to identify CYP21A2 carriers by SDSST, although basal 17-OHP level may not be informative. ROC curve analysis from studylevel data may produce some bias, and so the cut-off values from our results should be used with caution. In addition, the SDSST needs further investigation to increase specificity and sensitivity to determine heterozygosity. A greater increase in stimulated 17-OHP levels was found in mutation-free symptomatic individuals than those who were asymptomatic. Therefore, we suggest that individuals might be better evaluated by SDSST by considering the clinical phenotype and type of mutation to increase the accuracy of the test.

\section{Acknowledgments}

Thanks to Dr. Yasin Şimşek, an endocrinologist, for his contribution to the meta-analyses as a third opinion.

\section{Ethics}

Ethics Committee Approval: This study is a meta-analysis study.

Informed Consent: This study is a meta-analysis study.

Peer-review: Externally peer-reviewed.

\section{Authorship Contributions}

Surgical and Medical Practices: Seher Polat, Concept: Seher Polat, Yusuf Kemal Arslan, Design: Seher Polat, Yusuf Kemal Arslan, Data Collection or Processing: Seher Polat, Yusuf Kemal Arslan, Analysis or Interpretation: Seher Polat, Yusuf Kemal Arslan, Literature Search: Seher Polat, Yusuf Kemal Arslan, Writing: Seher Polat.

Financial Disclosure: The authors declared that this study received no financial support.

\section{References}

1. Azziz R, Sanchez LA, Knochenhauer ES, Moran C, Lazenby J, Stephens KC, Taylor K, Boots LR. Androgen excess in women: experience with over 1000 consecutive patients. J Clin Endocrinol Metabolism 2004;89:453-462

2. Barber TM, Franks S. Genetics of polycystic ovary syndrome. Front Horm Res 2013;40:28-39. Epub 2012 Oct 18

3. Panda PK, Rane R, Ravichandran R, Singh S, Panchal H. Genetics of PCOS: A systematic bioinformatics approach to unveil the proteins responsible for PCOS. Genom Data 2016;8:52-60.

4. Gharani N, Waterworth DM, Batty S, White D, Gilling-Smith C, Conway GS, McCarthy M, Franks S, Williamson R. Association of the steroid synthesis gene CYP11a with polycystic ovary syndrome and hyperandrogenism. Hum Mol Genet 1997;6:397-402.

5. Kahsar-Miller MD, Nixon C, Boots LR, Go RC, Azziz R. Prevalence of polycystic ovary syndrome (PCOS) in first-degree relatives of patients with PCOS. Fertil Steril 2001;75:53-58.

6. Robyr D, Llor J, Gaudin G, Schneider N. Polycystic ovary syndrome and congenital adrenal hyperplasia: a different entity for comparable phenotypes? Rev Med Suisse 2007;3:1595-1596.

7. Nandagopal R, Sinaii N, Avila NA, Van Ryzin C, Chen W, Finkielstain GP, Mehta SP, McDonnell NB, Merke DP. Phenotypic profiling of parents with cryptic nonclassic congenital adrenal hyperplasia: findings in 145 unrelated families. Eur J Endocrinol 2011;164:977-984. Epub 2011 Mar 28

8. New MI. Extensive clinical experience: nonclassical 21-hydroxylase deficiency. J Clin Endocrinol Metab 2006;91:4205-4214. Epub 2006 Aug 15

9. Siegel SF, Finegold DN, Urban MD, McVie R, Lee PA. Premature pubarche: etiological heterogeneity. J Clin Endocrinol Metab 1992;74:239-247.

10. del Balzo P, Borrelli P, Cambiaso P, Danielli E, Cappa M. Adrenal Steroidogenic Defects in Children with Precocious Pubarche. Horm Res 1992;37:180-184

11. Leite MV, Mendonça BB, Arnhold IJ, Estefan V, Nunes C, Nicolau W, Bloise W. Identification of nonclassical 21-hydroxylase deficiency in girls with precocious pubarche. J Endocrinol Invest 1991;14:11-15.

12. Azziz R, Owerbach D. Molecular abnormalities of the 21-hydroxylase gene in hyperandrogenic women with an exaggerated 17-hydroxyprogesterone response to short-term adrenal stimulation. Am J Obstet Gynecol 1995;172:914-918.

13. Hasinski S. Assessment of adrenal glucocorticoid function. Which tests are appropriate for screening? Postgrad Med 1998;104:61-64.

14. Azziz R, Rafi A, Smith BR, Bradley EL Jr, Zacur HA. On the origin of the elevated 17-hydroxyprogesterone levels after adrenal stimulation in hyperandrogenism. J Clin Endocrinol Metab 1990;70:431-436.

15. Dacou-Voutetakis C, Dracopoulou M. High incidence of molecular defects of the CYP21 gene in patients with premature adrenarche. J Clin Endocrinol Metab 1999;84:1570-1574.

16. Witchel SF, Aston CE. The role of heterozygosity for CYP21 in the polycystic ovary syndrome. J Pediatr Endocrinol Metab 2000;13(Suppl 5):1315-1317.

17. Blanché H, Vexiau P, Clauin S, Le Gall I, Fiet J, Mornet E, Dausset J, Bellanné-Chantelot $C$. Exhaustive screening of the 21-hydroxylase gene in a population of hyperandrogenic women. Hum Genet 1997;101:56-60.

18. Witchel SF, Lee PA, Suda-Hartman M, Hoffman EP. Hyperandrogenism and manifesting heterozygotes for 21-hydroxylase deficiency. Biochem Mol Med 1997;62:151-158.

19. Cisternino M, Dondi E, Martinetti M, Lorini R, Salvaneschi L, Cuccia M, Severi F. Exaggerated 17-hydroxyprogesterone response to short-term 
adrenal stimulation and evidence for CYP21 B gene point mutations in true precocious puberty. Clin Endocrinol (Oxf) 1998;48:555-560.

20. Ostlere LS, Rumsby G, Holownia P, Jacobs HS, Rustin MH, Honour JW. Carrier status for steroid 21-hydroxylase deficiency is only one factor in the variable phenotype of acne. Clin Endocrinol (Oxf) 1998;48:209215.

21. Polat S, Karaburgu S, Ünlühizarcı K, Dündar M, Özkul Y, Arslan YK, Karaca Z, Kelestimur F. Comprehensive genotyping of Turkish women with hirsutism. J Endocrinol Invest 2019;42:1077-1087. Epub 2019 Feb 27

22. Knochenhauer ES, Cortet-Rudelli C, Cunnigham RD, Conway-Myers BA, Dewailly D, Azziz R. Carriers of 21-hydroxylase deficiency are not at increased risk for hyperandrogenism. J Clin Endocrinol Metab 1997;82:479-485.

23. Escobar-Morreale HF, San Millán JL, Smith RR, Sancho J, Witchel SF. The presence of the 21-hydroxylase deficiency carrier status in hirsute women: phenotype-genotype correlations. Fertil Steril 1999;72:629638.

24. Moran C, Azziz R, Weintrob N, Witchel SF, Rohmer V, Dewailly D, Marcondes JA, Pugeat M, Speiser PW, Pignatelli D, Mendonca BB, Bachega TA, Escobar-Morreale HF, Carmina E, Fruzzetti F, Kelestimur F. Reproductive outcome of women with 21-hydroxylase-deficient nonclassic adrenal hyperplasia. J Clin Endocrinol Metab 2006;91:34513456. Epub 2006 Jul 5

25. Potau N, Rique S, Eduardo I, Marcos V, Ibanez L. Molecular defects of the CYP21 gene in Spanish girls with isolated precocious pubarche. Eur J Endocrinol 2002;147:485-488.

26. Cohen J. Statistical Power Analysis for the Behavioral Sciences. 1988.

27. Hariyanto TI, Japar KV, Kwenandar F, Damay V, Siregar JI, Lugito NPH, Tjiang MM, Kurniawan A. Inflammatory and hematologic markers as predictors of severe outcomes in COVID-19 infection: A systematic review and meta-analysis. Am J Emerg Med 2021;41:110-119. Epub 2020 Dec 30

28. Higgins JPT, Thompson SG, Deeks JJ, Altman DG. Measuring inconsistency in meta-analyses. BMJ 2003;327:557-560.

29. Pillemer RJLaDB. Summing Up: The Science of Reviewing Research. Harvard University Press, Cambridge, MA, 1984.

30. Neocleous V, Fanis P, Toumba M, Phedonos AAP, Picolos M, Andreou E, Kyriakides TC, Tanteles GA, Shammas C, Phylactou LA, Skordis N. Variations in the 3'UTR of the CYP21 A2 Gene in Heterozygous Females with Hyperandrogenaemia. Int J Endocrinol 2017;2017:8984365. Epub 2017 Apr 12

31. Settas N, Dracopoulou-Vabouli M, Dastamani A, Katsikis I, Chrousos G, Panidis D, Dacou-Voutetakis C. CYP21 A2 mutations in women with polycystic ovary syndrome (PCOS). Horm Metab Res 2013;45:383386. Epub 2013 Feb 5

32. Witchel SF, Lee PA, Suda-Hartman M, Trucco M, Hoffman EP. Evidence for a heterozygote advantage in congenital adrenal hyperplasia due to 21-hydroxylase deficiency. J Clin Endocrinol Metab 1997;82:20972101.

33. Witchel SF, Lee PA. Identification of heterozygotic carriers of 21-hydroxylase deficiency: sensitivity of ACTH stimulation tests. Am J Med Genet 1998;76:337-342.

34. Oriolo C, Fanelli F, Castelli S, Mezzullo M, Altieri P, Corzani F, Pelusi C, Repaci A, Di Dalmazi G, Vicennati V, Baldazzi L, Menabò S, Dormi A, Nardi E, Brillanti G, Pasquali R, Pagotto U, Gambineri A. Steroid biomarkers for identifying non-classic adrenal hyperplasia due to 21-hydroxylase deficiency in a population of PCOS with suspicious levels of 17OH-progesterone. J Endocrinol Invest 2020;43:1499-1509. Epub 2020 Mar 31
35. Napolitano E, Manieri C, Restivo F, Composto E, Lanfranco F, Repici M, Pasini B, Einaudi S, Menegatti E. Correlation between genotype and hormonal levels in heterozygous mutation carriers and non-carriers of 21-hydroxylase deficiency. J Endocrinol Invest 2011;34:498-501. Epub 2010 Jul 29

36. Bachega TA, Billerbeck AE, Marcondes JA, Madureira G, Arnhold IJ, Mendonca BB. Influence of different genotypes on 17-hydroxyprogesterone levels in patients with nonclassical congenital adrenal hyperplasia due to 21-hydroxylase deficiency. Clin Endocrinol (Oxf) 2000;52:601-607.

37. Costa-Barbosa FA, Tonetto-Fernandes VF, Carvalho VM, Nakamura $\mathrm{OH}$, Moura V, Bachega TA, Vieira JG, Kater CE. Superior discriminating value of ACTH-stimulated serum 21-deoxycortisol in identifying heterozygote carriers for 21-hydroxylase deficiency. Clin Endocrinol (Oxf) 2010;73:700-706.

38. Paris F, Tardy V, Chalançon A, Picot MC, Morel Y, Sultan C. Premature pubarche in Mediterranean girls: high prevalence of heterozygous CYP21 mutation carriers. Gynecol Endocrinol 2010;26:319-324.

39. Bidet M, Bellanné-Chantelot C, Galand-Portier MB, Tardy V, Billaud L, Laborde K, Coussieu C, Morel Y, Vaury C, Golmard JL, Claustre A, Mornet E, Chakhtoura Z, Mowszowicz I, Bachelot A, Touraine P, Kuttenn F. Clinical and molecular characterization of a cohort of 161 unrelated women with nonclassical congenital adrenal hyperplasia due to 21-hydroxylase deficiency and 330 family members. J Clin Endocrinol Metab 2009;94:1570-1578. Epub 2009 Feb 10

40. Grodnitskaya E, Kurtser M. The prevalence of non-classic congenital adrenal hyperplasia due to 21-hydroxylase deficiency in Russian women with hyperandrogenism. Hum Fertil (Camb) 2018;21:281-287. Epub 2017 Jul 3

41. Admoni O, Israel S, Lavi I, Gur M, Tenenbaum-Rakover Y. Hyperandrogenism in carriers of CYP21 mutations: the role of genotype. Clin Endocrinol (Oxf) 2006;64:645-651 .

42. Strott CA, Lipsett MB. Measurement of 17-hydroxyprogesterone in human plasma. J Clin Endocrinol Metab 1968;28:1426-1430.

43. Barnes ND, Atherden SM. Diagnosis of congenital adrenal hyperplasia by measurement of plasma 17-hydroxyprogesterone. Arch Dis Child 1972;47:62-65.

44. Laureti S, Arvat E, Candeloro P, Di Vito L, Ghigo E, Santeusanio F, Falorni A. Low dose (1 microg) ACTH test in the evaluation of adrenal dysfunction in pre-clinical Addison's disease. Clin Endocrinol (Oxf) 2000;53:107-115.

45. Dökmetaş HS, Colak R, Keleştimur F, Selçuklu A, Unlühizarci K, Bayram F. A comparison between the 1-microg adrenocorticotropin (ACTH) test, the short ACTH (250 microg) test, and the insulin tolerance test in the assessment of hypothalamo-pituitary-adrenal axis immediately after pituitary surgery. J Clin Endocrinol Metab 2000;85:3713-3719.

46. Unlühizarci K, Bayram F, Güven M, Kula M, Colak R, Kelestimur F. Cortisol responses to low (1 microg) and standard (250 microg) dose ACTH stimulation tests in patients with primary hypothyroidism. Clin Endocrinol (Oxf) 2001;54:700-702.

47. Kirnap M, Colak R, Eser C, Ozsoy O, Tutus A, Kelestimur F. A comparison between low-dose (1 microg), standard-dose (250 microg) ACTH stimulation tests and insulin tolerance test in the evaluation of hypothalamo-pituitary-adrenal axis in primary fibromyalgia syndrome. Clin Endocrinol (Oxf) 2001;55:455-459.

48. Colak R, Keleştimur F, Unlühizarci K, Bayram F, Sahin Y, Tutuş A. A comparison between the effects of low dose $(1$ microg) and standard dose (250 microg) ACTH stimulation tests on adrenal P450c17alpha enzyme activity in women with polycystic ovary syndrome. Eur J Endocrinol 2002;147:473-477. 
49. Turner EI, Watson MJ, Perry LA, White MC. Investigation of adrenal function in women with oligomenorrhoea and hirsutism (clinical PCOS) from the north-east of England using an adrenal stimulation test. Clin Endocrinol (Oxf) 1992;36:389-397.

50. Armengaud JB, Charkaluk ML, Trivin C, Tardy V, Bréart G, Brauner R, Chalumeau M. Precocious pubarche: distinguishing late-onset congenital adrenal hyperplasia from premature adrenarche. J Clin Endocrinol Metab 2009;94:2835-2840. Epub 2009 May 19

51. Peter M, Sippell WG, Lorenzen F, Willig RP, Westphal E, Grosse-Wilde $\mathrm{H}$. Improved test to identify heterozygotes for congenital adrenal hyperplasia without index case examination. Lancet 1990;335:12961299

52. Gutai JP, Kowarski AA, Migeon CJ. The detection of the heterozygous carrier for congenital virilizing adrenal hyperplasia. J Pediatr 1977;90:924-929.

53. Handelsman DJ, Howe CJ, Conway AJ, Turtle JR. Heterozygote detection in congenital adrenal hyperplasia. Clin Chem 1983;29:48-50.

54. Speiser PW, White PC. Congenital adrenal hyperplasia. N Engl J Med 2003;349:776-788.

55. Dracopoulou-Vabouli M, Maniati-Christidi M, Dacou-Voutetakis C. The spectrum of molecular defects of the CYP21 gene in the Hellenic population: variable concordance between genotype and phenotype in the different forms of congenital adrenal hyperplasia. J Clin Endocrinol Metab 2001;86:2845-2848.

56. New MI, Lorenzen F, Lerner AJ, Kohn B, Oberfield SE, Pollack MS, Dupont B, Stoner E, Levy DJ, Pang S, Levine LS. Genotyping steroid 21-hydroxylase deficiency: hormonal reference data. J Clin Endocrinol Metab 1983;57:320-326.

57. Fiet J, Villette JM, Galons H, Boudou P, Burthier JM, Hardy N, Soliman $H$, Julien R, Vexiau P, Gourmelen M, Kuttenn F. The application of a new highly-sensitive radioimmunoassay for plasma 21-deoxycortisol to the detection of steroid-21-hydroxylase deficiency. Ann Clin Biochem 1994;31:56-64.

58. Maffazioli GDN, Bachega TASS, Hayashida SAY, Gomes LG, Valassi HPL, Marcondes JAM, Mendonca BB, Baracat EC, Maciel GAR. Steroid
Screening Tools Differentiating Nonclassical Congenital Adrenal Hyperplasia and Polycystic Ovary Syndrome. J Clin Endocrinol Metab 2020;105:369

59. Temeck JW, Pang SY, Nelson C, New MI. Genetic defects of steroidogenesis in premature pubarche. J Clin Endocrinol Metab 1987;64:609-617.

60. Escobar-Morreale HF, Sanchón R, San Millán JL L. A prospective study of the prevalence of nonclassical congenital adrenal hyperplasia among women presenting with hyperandrogenic symptoms and signs. J Clin Endocrinol Metab 2008;93:527-533. Epub 2007 Nov 13

61. Gönç EN, Ozön ZA, Alikaşifoğlu A, Engiz O, Bulum B, Kandemir N. Is basal serum $17-\mathrm{OH}$ progesterone a reliable parameter to predict nonclassical congenital adrenal hyperplasia in premature adrenarche? Turk J Pediatr 2011;53:274-280.

62. Miller WL, Auchus RJ. The molecular biology, biochemistry, and physiology of human steroidogenesis and its disorders. Endocr Rev 2011;32:81-151. Epub 2010 Nov 4

63. Kulle AE, Riepe FG, Hedderich J, Sippell WG, Schmitz J, Niermeyer L, Holterhus PM. LC-MS/MS based determination of basal- and ACTHstimulated plasma concentrations of 11 steroid hormones: implications for detecting heterozygote CYP21 A2 mutation carriers. Eur J Endocrinol 2015;173:517-524.

64. Barr M. A study of genetic variability at the CYP11B2/B1 locus and its importance in human hypertension. University of Glasgow, 2006;1 296.

65. Nishi H, Kimura A, Harada H, Koga Y, Adachi K, Matsuyama K, Koyanagi T, Yasunaga S, Imaizumi T, Toshima H, Sasazuki T. A myosin missense mutation, not a null allele, causes familial hypertrophic cardiomyopathy. Circulation 1995;91:2911-2915.

66. Gotoda Y, Wakamatsu N, Kawai H, Nishida Y, Matsumoto T. Missense and nonsense mutations in the lysosomal alpha-mannosidase gene (MANB) in severe and mild forms of alpha-mannosidosis. Am J Hum Genet 1998;63:1015-1024. 